DOI: 10.14451/1.186.70

\title{
ГЕНЕЗИС И ЭФФЕКТИВНОСТЬ ФУНКЦИОНИРОВАНИЯ ПРОМЫШЛЕННЫХ КЛАСТЕРОВ В САНКТ-ПЕТЕРБУРГЕ *
}

\section{(c) 2020 Карлик Ефим Михайлович}

аспирант кафедры экономики и управления предприятиями и производственными комплексами Санкт-Петербургский государственный экономический университет, Россия, Санкт-Петербург

E-mail:fmkarlik@mail.ru

\section{(C) 2020 Кузяев Далер Адьямович}

аспирант кафедры экономики и управления предприятиями и производственными комплексами Санкт-Петербургский государственный экономический университет, Россия, Санкт-Петербург

E-mail: daler9593@mail.ru

В работе показан генезис и трансформация территориально-производственных объединений в полноценные по составу и структуре территориальные (региональные) инновационные кластеры. Рассмотрено кластерное построение промышленности Санкт-Петербурга. Проанализирована эффективность функционирования промышленных кластеров в Санкт-Петербурге (на примере Медико-фармацевтического кластера). Предложены методические основы экспресс-оценки эффективности деятельности кластеров на основе совокупности показателей, что позволит, учитывая динамику показателей рентабельности, финансовой устойчивости, долгосрочной и краткосрочной платежеспособности и индексов промышленного роста реализовать потенциал кластера.

Ключевые слова: анализ деятельности предприятий, промышленный кластер, территориальнопроизводственный комплекс, экспресс-оценка, промышленность.

Статья построена следующим образом: во введении рассматривается актуальность проблематики исследования, в первой части - генезис промышленных кластеров и ситуация в Санкт-Петербурге, во второй части - анализ деятельности компаний, входящих в Медикофармацевтический кластер, в заключении - основные выводы и возможные направления для дальнейших исследований.

Повышение эффективности функционирования региональных промышленных комплексов неразрывно связано с использованием современных форм организации производства на различных уровнях управления. Именно это и должно являться предметом реализации региональной промышленной политики, естественно, с учетом специфики региона и его места в разделении труда на национальном уровне. Соответственно, одним из ее направлений региональной промышленной политики, понимаемой как «комплекс правовых, экономических, организационных и иных мер, направленных на развитие промышленного потенциала региона, обеспечение производства на его терри- тории конкурентоспособной промышленной продукции» [1], должно стать стимулирование взаимодействия предприятий (в том числе повышение уровня специализации и кооперирования на региональном уровне) с целью роста их производительности за счет реализации синергетического эффекта. Целью данного исследования является обоснование методических основ экспресс-оценки эффективности кластерных образований, в определенной степени являющихся преемниками территориальнопроизводственных объединений.

Нужно отметить, что задача повышения уровня специализации и кооперирования как эффективной формы разделения труда и организации производства достаточно успешно решалась в условиях плановой директивной экономики в рамках формирования как территориальнопроизводственных комплексов, так и производственных (научно-производственных) объединений. Значительный вклад в разработку данной проблематики внесли такие известные ученые как Колосовский Н.Н. [8,9], Мильнер Б.3. [10], Карлик Е.М. [6], однако в рыночной эконо-

\footnotetext{
* Исследование выполнено при финансовой поддержке РФФИ в рамках научного проекта № 19-010-00257 «Методология анализа промышленных предприятий и отраслей нематериального производства в условиях информационного общества и цифровизации»
} 
мике прямое административное вмешательство и директивное планирование, в том числе в области региональных специализации и кооперирования, стало невозможным. Именно тогда появился (в России) феномен кластера как одной из форм организации производства на региональном уровне в виде, сформулированном Майклом Портером в 1993 году [12].

За прошедшие десятилетия понятие «кластер» претерпело достаточное количество толкований, в том числе в российской экономике. Для определения кластеров в нашем исследовании будем использовать требования, указанные в Постановлении Правительства РФ от 31.07.2015 N 779 «О промышленных кластерах и специализированных организациях промышленных кластеров» [2] (далее по тексту - Постановление), что позволит выделить объединения предприятий, соответствующих зафиксированным в нормативных документах критериям. Если опираться на критерии Постановления, использование, например, понятия «автомобильный кластер» в рамках Санкт-Петербурга является некорректным, поскольку кластерное построение предполагает именно взаимодействие между предприятиями кластера, а не просто наличие ряда отдельных компаний, выпускающих продукцию соответствующего назначения.

В настоящий момент в Санкт-Петербурге в соответствии с Постановлением функционируют 4 промышленных кластера [14], (все начального уровня организационного развития), а именно:

- Медико-фармацевтический кластер, созданный в 2011 году - 13 участников (поддерживается центром кластерного развития в рамках программы Минэкономразвития России по поддержке малого и среднего предпринимательства);

- Промышленный кластер «Кластер медицинского, экологического приборостроения и биотехнологий Санкт-Петербурга», созданный в 2015 году - 50 участников;

- Кластер производителей средств электронно-вычислительной техники, созданный в 2017 году - 12 участников (включен в Реестр Промышленных кластеров, утверждаемый Минпромторгом);

- Кластер. СПГ. Оборудование и технологии, созданный в 2018 году - 10 участников (включен в Реестр Промышленных кластеров, утверждаемый Минпромторгом).
Порядок внесения промышленного кластера в реестр Минпромторга, как было указано выше, регламентируется Постановлением [6], устанавливающим требования в части уровня кооперации (закупка производителями готовой продукции не менее 20\% у промежуточных производителей); числу высокопроизводительных рабочих мест (не менее 50\%) и числу участников, осуществляющих производство промышленной продукции (не менее 10).

Как известно, промышленные кластеры, вошедшие в реестр Минпромторга, в соответствии с Постановлением правительства РФ от 28 января 2016 года № 41 «Об утверждении Правил предоставления из федерального бюджета субсидий участникам промышленных кластеров на возмещение части затрат при реализации совместных проектов по производству промышленной продукции кластера в целях импортозамещения» [3], могут рассчитывать на субсидирование до 50\% понесенных затрат на нужды производства и уплату до 70\% по кредитам, полученным на любые нужны, необходимые для производства (оборудование, программное обеспечение, строительно-монтажные работы и др.), что безусловно является теми мерами поддержки, что могут оказать существенное влияние на финансовое состояние предприятия. До 2021 года промышленные кластеры в виде субсидий получат около 6 млрд. руб. Оценить достаточность этой суммы в рамках поддержки кластерных образований и возможность ее получения особенно затруднительно в настоящий период, что связано со значительными выпадающими доходами бюджета, в том числе за счет падения цен на нефть и затрат на противостояние пандемии коронавируса.

Промышленные кластеры, не включенные в реестр Минпромторга, на федеральные субсидии рассчитывать не могут, однако существуют определенные региональные меры поддержки, в частности такие, как программы поддержки субъектов малого и среднего предпринимательства, налоговые льготы, возмещение части затрат и др.

Исходя из значения эффективности непрямых мер стимулирования развития промышленности, проведем оценку функционирования кластерного образования, не получающего федеральную поддержку и в качестве объекта рассмотрим Медико-фармацевтический кластер (далее по тексту - Кластер), который как нельзя 
лучше подходит для этих целей, в связи со сравнительно небольшим количеством участников и длительным периодом функционирования (10 лет), что позволяет предположить наличие значительного экономического эффекта от его деятельности.

Нужно отметить, что существует ряд методических материалов по оценке экономической эффективности формирования и функционирования кластеров, в частности, разработки Клепиковой Н.И. [7], Патрушевой Е.Г. и Большаковой Е.А. [5], Тюкавкина Н. М. [13], Морозовой Е.В. [11] и других авторов.

Тем не менее, учитывая непосредственно показатели деятельности кластеров, авторы не всегда проводят сравнительный анализ эффективности кластеров и эффективности функционирования региональных промышленных комплексов и соответствующих отраслей (видов производств) на федеральном уровне, что и требует корректировки соответствующих подходов.

Большинство компаний - участников Кластера по своей юридической форме являются обществами с ограниченной ответственностью и акционерными обществами, что не обязывает их публиковать отчетность. В открытых источниках представлена информация о финансовых результатах этих компаний за 2018 г. и ранее (на основании данных Росстата и Федеральной налоговой службы). Для целей исследования проанализируем финансовые показатели компаний-участников кластера за период с 2016 по 2018 год (выборка 4 компании) и сравним с показателями аналогичных компаний региона по основному виду деятельности «производство лекарственных препаратов» (выборка 4 компании). Динамику изменения выручки сравним с индексом промышленного роста Санкт-Петербурга, индексом отраслевого роста медико-фармацевтической отрасли Российской Федерации и ВВП Российской Федерации. Стоит отметить, что ряд компаний присоединились к Кластеру в 2015 году, в связи с чем анализируется период с 2016 года, так как по предположению авторов, ожидать какого-либо эффекта именно от присоединения возможно не ранее чем через год.

Участников Кластера можно разделить на три группы с точки зрения конечного продукта:

- производители активных фармацевтических субстанций;

- производители готовых лекарственных форм;

- производители готовых лекарственных форм полного цикла.

Данная структура предполагает высокий уровень внутренней инновационной кооперации и в перспективе, при соблюдении других требований, определенных законодательством, позволит Кластеру войти в реестр Минпромторга с получением всех сопутствующих льгот.

Эффективность деятельности компаний может быть оценена совокупностью следующих традиционных показателей: рентабельность собственного капитала (ROE); рентабельность продаж (ROS); рентабельность инвестированного капитала (ROIC); коэффициент покрытия инвестиций; фондоотдача; коэффициенты автономии, финансовой устойчивости, абсолютной ликвидности, текущей ликвидности. Формулы расчета данных показателей общеизвестны, поэтому в данной статье они не приводятся.

На основании расчетов, результаты которых представлены в табл.1, можно сделать вывод, что компании-участники кластера при сопоставимости рентабельности операционной деятельности (ROS) рациональнее используют имеющиеся ресурсы: у них выше отдача на капитал. Получается, что обеспечение деятельности компаний, входящих, в Кластер, требует меньшего количества активов, а также определяет возможность более активного привлечения заемного капитала. Также можно отметить, что динамика изменений средних значений показателей финансовой устойчивости и долгосрочной/краткосрочной платежеспособности одинакова во всех компаниях: как участников кластера, так и не входящих в него. Несмотря на то, что оптимальные значения этих показателей в первую очередь зависят от структуры активов компании, можно сделать вывод, что данные показатели в компаниях - не участников кластера выше и, возможно, с точки зрения эффективности, избыточны. Однако, в том числе и от значения данных показателей зависит возможность привлечения заёмного капитала.

Несмотря на положительную динамику банковского кредитования нефинансового сектора за последние годы (в 2018 году - прирост 5,8\%, в 2017-3,7\%) [15] и официальную средневзвешенную процентную ставку по рублевым кредитам на срок свыше 1 года в размере 10\% годовых (при инфляции 4,2\% в 2018 году и 2,5\% в 2017 году, соответственно) [16], условия получения 
Таблица 1. Финансовые показатели компаний, входящих в Кластер и функционирующих вне Кластера

\begin{tabular}{|c|c|c|c|}
\hline & & Ср. знач. компаний Кластера & Ср. знач. компаний вне Кластера \\
\hline \multirow{3}{*}{ ROE } & 2016 & 0,61 & 0,22 \\
\hline & 2017 & 0,51 & 0,13 \\
\hline & 2018 & 0,34 & 0,10 \\
\hline \multirow{3}{*}{ ROS } & 2016 & 0,23 & 0,14 \\
\hline & 2017 & 0,19 & 0,16 \\
\hline & 2018 & 0,21 & 0,21 \\
\hline \multirow{3}{*}{$\begin{array}{c}\text { Коэффициент покрытия } \\
\text { инвестиций }\end{array}$} & 2016 & 0,62 & 0,79 \\
\hline & 2017 & 0,65 & 0,87 \\
\hline & 2018 & 0,70 & 0,87 \\
\hline \multirow{3}{*}{ Рентабельность } & 2016 & 0,42 & 0,64 \\
\hline & 2017 & 0,40 & 0,59 \\
\hline & 2018 & 0,40 & 0,59 \\
\hline \multirow{3}{*}{ ROIC } & 2016 & 0,27 & 0,07 \\
\hline & 2017 & 0,27 & 0,06 \\
\hline & 2018 & 0,16 & 0,12 \\
\hline \multirow{3}{*}{ Фондоотдача } & 2016 & 8,17 & 3,10 \\
\hline & 2017 & 7,48 & 2,28 \\
\hline & 2018 & 5,64 & 1,09 \\
\hline \multirow{3}{*}{ Коэффициент автономии } & 2016 & 0,47 & 0,67 \\
\hline & 2017 & 0,53 & 0,57 \\
\hline & 2018 & 0,47 & 0,59 \\
\hline \multirow{3}{*}{$\begin{array}{c}\text { Коэффициент финансовой } \\
\text { устойчивости }\end{array}$} & 2016 & 0,64 & 0,80 \\
\hline & 2017 & 0,67 & 0,87 \\
\hline & 2018 & 0,71 & 0,88 \\
\hline \multirow{3}{*}{$\begin{array}{c}\text { Коэффициент абсолютной } \\
\text { ликвидности }\end{array}$} & 2016 & 0,20 & 2,64 \\
\hline & 2017 & 0,33 & 12,54 \\
\hline & 2018 & 0,27 & 3,30 \\
\hline \multirow{3}{*}{$\begin{array}{c}\text { Коэффициент текущей } \\
\text { ликвидности }\end{array}$} & 2016 & 2,35 & 9,15 \\
\hline & 2017 & 3,35 & 20,31 \\
\hline & 2018 & 2,50 & 8,80 \\
\hline
\end{tabular}

кредитов и текущая финансово-экономическая ситуация не позволяли привлекать финансирование в достаточном объеме, для обеспечения инновационного развития даже с учетом существования ряда фондов поддержки промышленности, в частности, Фонда развития промышленности Санкт-Петербурга, Фонда содействия инновациям и других. Возможности привлечения «длинного и дешевого» зарубежного финансирования в последние годы также ограничены. В связи с этим, задача большинства промышленных компаний - поддержка уровня безубыточности и получение максимально возможной прибыли для владельцев. При этом вопросы инвестирования в инновации, обновление ос- новных фондов, развитие кластерных инициатив часто отходят на второй план. Исходя из того, что фармацевтическая отрасль является капиталоемкой в части затрат на оборудование и научно-исследовательские работы и имеет продолжительный исследовательский цикл, возможность привлечения льготного финансирования и различных субсидий может стать решающим фактором при оценке необходимости формирования и развития промышленных кластеров.

В табл.2 представлена динамика изменения совокупности показателей, необходимых для оценки роста компаний.

На основании табл.2 можно сделать вывод, 
Таблица 2. Индексы изменения показателей для анализа роста компаний

\begin{tabular}{|l|c|c|c|}
\hline \multicolumn{1}{|c|}{ Индексы изменения } & 2016 & 2017 & 2018 \\
\hline ВВП РФ [17] & $0,3 \%$ & $1,6 \%$ & $2,3 \%$ \\
\hline Промышленное производство СПб [18] & $103,9 \%$ & $105,5 \%$ & $105,5 \%$ \\
\hline Фармацевтический рынок РФ [19] & $6,7 \%$ & $7,9 \%$ & $2,6 \%$ \\
\hline Средний рост компаний-участников Кластера & $19 \%$ & $18 \%$ & $16 \%$ \\
\hline Средний рост компаний вне Кластера & $18 \%$ & $3 \%$ & $7 \%$ \\
\hline
\end{tabular}

что в период с 2016 по 2018 года компанииучастники Кластера увеличили свою долю на фармацевтическом рынке Российской федерации: их выручка росла быстрее, чем рынок в целом. Стоит отметить, что до 2018 года динамика отраслевых показателей была лучше, чем динамика изменений ВВП Российской Федерации и индекса промышленного производства СанктПетербурга, что является положительным фактором для фармацевтических компаний. Резкое снижение темпов роста в 2018 году связано с падением реально располагаемых доходов населения, ослаблением рубля и законодательными изменениями в части методики ценообразования на некоторые виды лекарственных препаратов.

Конечно, возможности приведенного подхода ограничены и использовать его можно лишь для первичной приблизительной оценки эффективности кластеров, однако не только на уровне региональных промышленных комплексов, но и на уровне макрорегионов, каковыми по сути являются некоторые федеральные округа, в частности Северо-Западный федеральный округ (далее по тексту - СЗФО). Кроме того, этот подход дает возможность экспресс-оценки потенциальной эффективности кластеров.

С этой точки зрения перспективным является использование данного подхода для оценки эффективности формирования и функционирования кластера СЗФО, связанного с развитием газомоторного транспорта. Существующая подпрограмма «Развитие рынка газомоторного топлива» являющаяся дополнением к Государственной программе Российской Федерации «Развитие энергетики» предполагает рост объема потребления природного газа в качестве моторного топлива до 2720 млн. куб. метров по итогам 2024 года [4], что практически в 3 раза выше, чем результаты 2019 года (приблизительно 1 млрд. куб. метров). При этом показатели Программы постоянно корректировались в связи с недостижением показателей, установленных в документах 2013 года (потребление компримированного газа в качестве моторного топлива в объеме 10400 млн. куб. метров в год. к 2020 году), соответственно, оценка потенциальной эффективности кластера позволит корректировать инструменты роста.

Опыт Медико-фармацевтического кластера позволяет говорить о необходимости четкого построения архитектуры нового формирования, определения состава участников, с тем, чтобы внутренняя кооперация охватывала весь производственный и закупочно-сбытовой цикл.

По результатам исследования можно сделать вывод, что, несмотря на начальный уровень развития кластерных образований, как в Российской Федерации, так и в Санкт-Петербурге, уже сейчас достигнут определенный эффект, оценка которого является фундаментально важной для формирования программных документов, связанных с развитием различных отраслей промышленности. Необходимо, чтобы кластеры, являясь институтами формальными, обеспечивали взаимодействие не исключительно ради получения «благ» от государства, а создавали реальные условия для кооперации их участников: именно такие промышленные объединения способны формировать значительное снижение транзакционных издержек, что положительно скажется на всех субъектах экономических отношений - от потребителей до государства.

В качестве основных направлений дальнейших исследований в данной области можно выделить разработку системы сбалансированных показателей для применения в семантической модели, что позволит реализовать интегральный подход к измерению эффективности деятельности предприятий промышленного сектора экономики, участвующих в кластерных образованиях и разработку оптимальной системы и структуры управления промышленными кластерами. 


\section{Библиографический список}

1. Федеральный закон «О промышленной политике в Российской Федерации» от 31.12.2014 N 488 -Ф3 (последняя редакция).

2. Постановление Правительства РФ от 31.07.2015 N 779 (ред. от 02.08.2018) «О промышленных кластерах и специализированных организациях промышленных кластеров».

3. Постановление Правительства РФ от 28.01.2016 N 41 (ред. от 06.10.2017) «Об утверждении Правил предоставления из федерального бюджета субсидий участникам промышленных кластеров на возмещение части затрат при реализации совместных проектов по производству промышленной продукции кластера в целях импортозамещения».

4. Постановление Правительства РФ от 02.03.2020 N 221 «О внесении изменений в государственную программу Российской Федерации «Развитие энергетики»

5. Большакова, Е.А., Патрушева, Е.Г. Оценка экономической эффективности регионального инновационного кластера / Большакова Е.А., Патрушева Е.Г., // Управление экономическими системами: электронный научный журнал. - 2015.- № 4 (76). - С. 1-22.

6. Карлик, E. М. Практика концентрации и специализации производства в объединениях и ее эффективность / Карлик Е. М., Силкина Т.Ф. // - Л.: ЛДНТП, 1976.-27 с.

7. Клепикова, Н. И. Оценка эффективности создания отраслевого кластера // Фундаментальные исследования / Клепикова Н.И.-2013. - № 4-4.- С. 934-939

8. Колосовский, Н. Н. Основы экономического районирования / Колосовский Н. Н.// - М.: Госполитиздат, 1958. 200 c.

9. Колосовский, Н.Н. Теория экономического районирования / Колосовский Н. Н.// - М.: Мысль, 1969. 335 с.

10. Мильнер, Б. З. Научно-технический прогресс и системный подход к управлению предприятием. / Мильнер Б.3.//- М.: б.и., 1969.- 13 с.

11. Морозова, Е. В. Методический подход к оценке эффективности деятельности участников пространственного кластера / Морозова Е. В. // Вопросы экономики и права. 2019. - № 1 (127)

12. Портер, М. Международная конкуренция: Конкурентные преимущества стран. / Портер M./ - М.: Международные отношения, 1993.- 895 с.

13. Тюкавкин, Н.М. Методы оценки эффективности функционирования кластеров в промышленности / Тюкавкин Н. М.// Основы экономики, управления и права.-2013. - № 3 - (9). С. 109-113.

14. Геоинформационная система. Индустриальные парки. Технопарки. Кластеры // [Электронный ресурс] URL: https://www.gisip.ru/ (дата обращения: 13.03.2020 г.)

15. О развитии банковского сектора Российской Федерации. Информационно-аналитический материал 20162018 // [Электронный ресурс] URL: https://www.cbr.ru/ (дата обращения: 17.03.2020 г.).

16. Росстат. Потребительские цены. Индексы потребительских цен на товары и услуги. // [Электронный ресурс] URL: https://www.gks.ru/free_doc/new_site/prices/potr/tab-potr1.htm (дата обращения: 17.03.2020 г.).

17. Росстат. Национальные счета. Валовый внутренний продукт // [Электронный ресурc] URL: https://www.gks. ru/accounts. (дата обращения: 17.03.2020 г.).

18. Справочник «Промышленность и инновации Санкт-Петербурга» - 2016-2018 // [Электронный pecypc] URL: https://cppi.gov.spb.ru/promishlennost_i_apk/itogi-razvitiya-prom/. (дата обращения: 18.03.2020 г.).

19. Тенденции фармацевтического рынка России 2017-2019. Исследовательский центр компании «Делойт» в СНГ // [Электронный ресурс] URL: https://www2.deloitte.com/ru/ru/industries/life-sciences-and-healthcare. html?icid=top_life-sciences-and-healthcare. (дата обращения: 18.03 .2020 г.). 